\title{
1999 NSW OLDER PEOPLE'S HEALTH SURVEY: AN OPPORTUNITY TO MONITOR THE HEALTH AND WELLBEING OF OLDER PEOPLE IN THE COMMUNITY
}

Deborah Baker and Margaret Williamson

Health Survey Program Unit, NSW Department of Health

\section{Hal Kendig}

Faculty of Health Sciences, University of Sydney

\section{Susan Quine}

Department of Public Health and Community Medicine, University of Sydney

1999 is the United Nations International Year of Older Persons, a year that highlights the need' to give priority attention to the situation of older persons in our community to ensure that they can maintain their independence, participation, care, self-fulfilment and dignity. The rapid growth of the generation of older people living into their eighties demands attention to their distinctive health needs, and to their increasing need for health and aged care services.

The document NSW Strategic Directions for Health 1998-2003 has underscored the importance of achieving health gains and preventing ill health throughout life for all people in NSW. ${ }^{1}$ Moreover, positive action requires not only delivery of service, but also extends to providing supportive physical and social environments and enabling individuals to take responsibility for their own health. Similarly, the overall goal of the NSW Healthy Ageing Framework 1998-2003 is to improve the opportunities for all older people to remain as independent and healthy as possible and able to participate in community life'. ${ }^{2}$ This framework emphasises the importance of appreciating the diversity of ageing people in terms of their gender, disability, and cultural background.

Research evidence increasingly indicates that individuals and governments can contribute significantly to maintaining health and wellbeing in aged populations. Information describing the experiences of older people can provide a basis for effective and positive action by individuals themselves, health professionals, and governments.

In partnership with the NSW Ageing and Disability Department and the 17 NSW Area Health Services, the NSW Department of Health is conducting the 1999 Older People's Health Survey. The survey will enhance our knowledge about the health and wellbeing of older people, the personal and social factors that influence them, and their need for health and aged care services. The emphasis of the survey is on health outcomes that are important to older people themselves, and which have reasonable prospects for improvement and prevention; and which can contribute to cost-effective health and aged care services.

\section{ABOUTTHE 1999 OLDER PEOPLE'S HEALTH SURVEY}

Interviewing for the survey began in August 1999 and will continue until November 1999. About 500 people aged 65 years and older will be interviewed by telephone in each of the 17 NSW Area Health Services. Telephone numbers have been chosen at random from the NSW White Pages directories.

Priority topics in the survey include:

- independence

- contributions to the community

- physical and mental health

- physical and social environmental influences on health

- behaviours that influence better health, such as exercise and diet

- use of and need for health and community services.

The survey takes 25 to 30 minutes for most people to complete. Participation is voluntary and those people who are interviewed are free to withdraw from the interview at any time. Any information provided by participants is held in complete confidence.

The survey questionnaire has been translated into Chinese, Greek, Italian and Arabic, and bilingual interviewers are available to conduct interviews in these languages.

It is anticipated that results will be available in June 2000 and that they will provide a basis for evaluating current strategies and developing new programs to improve the health and wellbeing of older people across the state.

\section{REFERENCES}

1. NSW Department of Health. Strategic Directions for Health 1998-2003. Sydney: NSW Department of Health, 1998.

2. NSW Department of Health. NSW Healthy Ageing Framework 1999-2003. Sydney: Ageing and Disability Department, NSW Department of Health, 1998.

Further information about the survey can be obtained from the Departmental Web site at www.health.nsw.gov.au/public-health/survey/ ophs99.html, by emailing Margaret Williamson at mwill@doh.health.nsw.gov.au, or by telephoning 1800620277. 